\title{
Improvement of Subjective Well-Being by Ranolazine in Patients with Chronic Angina and Known Myocardial Ischemia (IMWELL Study)
}

\author{
Anthony A. Bavry - Ki E. Park - Calvin Y. Choi - Ahmed N. Mahmoud · \\ Xuerong Wen · Islam Y. Elgendy
}

Received: November 18, 2016 / Published online: January 2, 2017

(C) The Author(s) 2016. This article is published with open access at Springerlink.com

\begin{abstract}
Introduction: We aimed to assess if ranolazine would improve angina symptoms among patients with documented myocardial ischemia.
\end{abstract}

Methods: Eligible subjects had chronic stable angina and at least one coronary stenosis with fractional flow reserve (FFR) $\leq 0.80$ or at least one chronic total occlusion (CTO) without attempted revascularization. Subjects were randomized to oral ranolazine $500 \mathrm{mg}$ twice daily for 1 week, then ranolazine $1000 \mathrm{mg}$ twice daily for 15 weeks versus matching placebo. The primary end point was

Enhanced content To view enhanced content for this article go to www.medengine.com/Redeem/ 3F47F06008C8FE80.

A. A. Bavry $(\bowtie) \cdot$ K. E. Park · C. Y. Choi ·

A. N. Mahmoud · X. Wen · I. Y. Elgendy

Department of Medicine, University of Florida,

Gainesville, FL, USA

e-mail: anthony.bavry@va.gov

A. A. Bavry · K. E. Park - C. Y. Choi

North Florida/South Georgia Veterans Health

System, Gainesville, FL, USA

X. Wen

Health Outcomes, College of Pharmacy, University

of Rhode Island, Kingston, RI, USA change in angina at 16 weeks as assessed by the Seattle Angina Questionnaire (SAQ).

Results: Between September 2014 and January 2016, 25 subjects were randomized to ranolazine versus 25 to placebo. The most common reason for eligibility was CTO (72\%), while the remainder had myocardial ischemia documented by low FFR. The mean FFR was $0.57 \pm 0.12$. Sixty-eight percent of subjects were on two or more anti-angina medications at baseline. Study medication was discontinued in $32 \%$ (eight of 25) of the ranolazine group versus $36 \%$ (nine of 25) of the placebo group. By intention-to-treat, 46 subjects had baseline and follow-up SAQ data completed. Ranolazine was not associated with an improvement in angina compared with placebo at 16 weeks. The results were similar among 33 subjects that completed study medication. The incidence of ischemia-driven hospitalization or catheterization was $12 \%$ (three of 25 ) of the ranolazine group versus $20 \%$ (five of 25 ) in the placebo group $(p>0.05)$.

Conclusions: In subjects with chronic stable angina and documented myocardial ischemia, ranolazine did not improve angina symptoms at 16 weeks. 
Funding: Gilead.

Clinical trial registration: The study was registered at ClinicalTrials.gov (NCT02265796).

Keywords: Angina; Coronary artery disease; Ranolazine; Randomized controlled trial; Revascularization; Stable

\section{INTRODUCTION}

Revascularization by percutaneous coronary intervention (PCI) or coronary artery bypass grafting (CABG) is feasible for the majority of patients with symptomatic ischemic heart disease, with resolution of their symptoms. However, many of these patients continue to have angina symptoms due to residual ischemia, which can result in repeat revascularizations and adverse cardiovascular events [1, 2]. Ranolazine is an anti-ischemia/ anti-angina medication that inhibits the late sodium current but does not affect the heart rate or blood pressure [3]. Ranolazine was associated with a reduction in recurrent ischemia among patients with acute coronary syndrome and history of angina [4]. In the Ranolazine for Incomplete Vessel Revascularization Post-Percutaneous Coronary Intervention (RIVER-PCI) multicenter randomized trial, ranolazine failed to reduce ischemia-driven hospitalization or ischemia-driven revascularization in chronic angina patients with incomplete revascularization [5]. However, incomplete revascularization was assessed angiographically, which is known to only modestly correlate with underlying myocardial ischemia [6, 7].

Therefore, we aimed to assess whether ranolazine would improve angina symptoms and subjective well-being among patients with documented myocardial ischemia, defined by either low fractional flow reserve (FFR) or presence of a chronic total occlusion (CTO), and who did not undergo revascularization.

\section{METHODS}

\section{Study Design and Selection Criteria}

This was a randomized single-center trial that enrolled subjects at least 18 years of age who were referred for catheterization for evaluation of angina, fatigue, or shortness of breath. This investigator initiated study was sponsored by Gilead Sciences. In addition to symptoms compatible with chronic stable angina, we required the following: (1) at least one borderline coronary stenosis with documented myocardial ischemia by FFR $(\leq 0.8)$ or at least one CTO, and (2) no attempted revascularization of the ischemic artery. CTO was defined as an occlusion in a $\geq 2 \mathrm{~mm}$ epicardial coronary artery in which distal flow was provided by antegrade or retrograde collaterals. An occlusion which was supplied by a patent bypass graft was not considered a CTO. The assumed FFR value of a CTO was 0.5 [8]. The decision not to revascularize an ischemic lesion was left to individual operator discretion, but included the following reasons: patient preference for initial medical therapy, lesion characteristics that increased the risk for restenosis (diffuse disease in a small vessel), or characteristics that increased the risk for procedural complication (severe calcification, excessive angulation/tortuosity, or inability to protect a bifurcation lesion). The following patients were excluded; coronary revascularization within the index procedure or planned in the next month, acute coronary syndrome or cardiogenic shock, use of strong 
inhibitors of CYP3A, use of inducers of CYP3A, liver cirrhosis, severe renal insufficiency (creatinine clearance $<30 \mathrm{ml} / \mathrm{min} / 1.73 \mathrm{~m}^{2}$ ), or baseline corrected QT interval $>500 \mathrm{~ms}$.

\section{Randomization}

Eligible subjects were randomly assigned to receive either oral ranolazine $500 \mathrm{mg}$ twice daily for 1 week, then ranolazine $1000 \mathrm{mg}$ twice daily for 15 weeks vs. matching placebo (one tablet twice daily for 1 week, then two tablets twice daily for 15 weeks). Randomization was performed with Excel 2010 utilizing the RAND function. A sample size of 50 was randomized using a simple schema with two levels representing treatment assignments without stratification. Block size was set at 10 . Study investigator, patient, and research team were blinded to treatment assignment. The treatment assignment code was kept by research pharmacy.

\section{Endpoints and Statistics}

The primary end point was change in angina from baseline to 16 weeks as assessed by the Seattle Angina Questionnaire (SAQ) [9]. Secondary endpoints included subjective well-being, in which subjects were asked, "in the last month, how would you rate your overall feeling of well-being (poor, fair, good, or excellent) [10]." Lastly, the incidence of ischemia-driven hospitalization or catheterization was assessed. Baseline characteristics were described as frequencies for categorical variables and means, with standard deviations, for continuous variables. Student's $t$ test, and the $\chi^{2}$ test were used for the comparison of the continuous and categorical variables, respectively. Paired $t$ test was used to compare the changes within a group. Statistical significance level was defined as $p<0.05$. All statistical analysis was conducted using SAS 9.4 (SAS Institute, Inc., Cary, NC, USA). We conducted power analysis based on the SAQ results measured in a previous study [11]. We hypothesized that patients at baseline would have a mean $\pm \mathrm{SD}$ of $53 \pm 23$ for physical limitation, $64 \pm 28$ for angina frequency, $53 \pm 28$ for angina stability, $79 \pm 19$ for treatment satisfaction, and $50 \pm 22$ for disease perception [2]. Assuming a 20\% change after follow up 16 weeks, it was estimated that 14-53 patients in each domain would give an $80 \%$ of power to detect a statistically significant difference between baseline and follow up $(\alpha=0.05)$.

\section{Safety and Ethics}

Institutional review board approval was obtained from the University of Florida. The study was registered at ClinicalTrials.gov (NCT02265796). An independent data safety monitor periodically reviewed adverse events to evaluate if there were any potential safety issues. All procedures followed were in accordance with the ethical standards of the responsible committee on human experimentation (institutional and national) and with the Helsinki Declaration of 1964, as revised in 2013. Informed consent was obtained from all patients for being included in the study.

\section{RESULTS}

Between September 2014 and January 2016, 25 subjects were randomized to ranolazine versus 25 to placebo. Follow-up SAQ was not obtained in four subjects. This was due to one death, and two study withdrawals in the ranolazine group and one study withdrawal in the placebo group. 
Table 1 Baseline characteristics

\begin{tabular}{lccc}
\hline & $\begin{array}{l}\text { Ranolazine } \\
(\boldsymbol{n}=\mathbf{2 5})\end{array}$ & $\begin{array}{l}\text { Placebo } \\
(\boldsymbol{n}=25)\end{array}$ & $\boldsymbol{p}$ value \\
\hline Past medical history $(\%)$ & 100 & $>0.99$ \\
Hypertension & 100 & 67 & 0.83 \\
Hyperlipidemia & 64 & 63 & 0.58 \\
Diabetes mellitus & 55 & 29 & 0.50 \\
On insulin & 18 & 54 & 0.10 \\
h/o PCI & 77 & 25 & 0.61 \\
h/o CABG & 32 & & \\
\hline
\end{tabular}

$C A B G$ coronary artery bypass grafting, $b / o$ history of, $P C I$ percutaneous coronary intervention

The most common reason for anatomic eligibility was chronic total occlusion that was present in $72 \%$, while the remainder had myocardial ischemia documented by FFR (mean FFR value was $0.57 \pm 0.12$ ). The mean age was 67 years \pm 9 years, mean left ventricular ejection fraction was $53 \pm 11 \%$, and mean left ventricular end diastolic pressure was 12 $\pm 5 \mathrm{mmHg}$. Sixty-eight percent of subjects were on two or more anti-angina therapies at baseline $(80 \%$ on a beta-blocker, $60 \%$ on a long-acting nitrate, and $35 \%$ on a calcium channel antagonist). Additional baseline characteristics are provided in Table 1.

Discontinuation of study medication occurred in $32 \%$ (eight of 25) of the ranolazine group at a mean of $55 \pm 46$ days (median, 46 days) versus $36 \%$ (nine of 25 ) of the placebo group at a mean of $31 \pm 27$ days (median, 31 days $) \quad(p>0.05)$. Dizziness or impaired memory was reported in $20 \%$ (five of 25 ) of the ranolazine group versus $12 \%$ (three of $25)$ in the placebo group $(p>0.05)$. Other reasons for drug discontinuation in the ranolazine arm included: tiredness (one patient), started on another QT prolonging medication (i.e., primidone), and one patient stopped the medication for no clear reason.

By intention-to-treat, 46 subjects had baseline and follow-up SAQ data completed at 16 weeks. Three out of five SAQ domains improved from baseline to follow-up in both groups (Angina Stability, Angina Frequency, and Quality of Life); however, there was no difference between the treatment and placebo groups (Table 2). There was no within-group change in Physical Limitation, or Treatment Satisfaction (Table 2). There was also no change in subjective well-being over the follow-up period (Table 3). The results were similar among 33 subjects that completed study medication.

At 16 weeks, the incidence of ischemia-driven hospitalization or catheterization was three out of 25 in the ranolazine group versus five out of 25 in the placebo group $(p>0.05)$.

\section{DISCUSSION}

Among patients with documented myocardial ischemia (mean FFR $=0.57$ ) and no attempted revascularization, ranolazine failed to improve angina symptoms or subjective well-being compared with placebo. Findings were the same by intention-to-treat analysis and also among the cohort that completed their treatment assignment. As a secondary outcome, incidence of ischemia-driven hospitalization or catheterization was similar between treatment groups. Discontinuation of study medication was high, but similar between groups and there was no appreciable difference in adverse events between treatment groups.

Lack of benefit could be due to good background medical therapy (68\% on two or 
Table 2 Change in Seattle Angina Questionnaire from baseline to 16 weeks

\begin{tabular}{lllll}
\hline $\begin{array}{l}\text { Seattle Angina } \\
\text { Questionnaire }\end{array}$ & Ranolazine $(n=22)$ & Placebo $(n=24)$ & $\begin{array}{l}\text { Intention-to-treat } \\
\text { analysis, between-group }\end{array}$ & $\begin{array}{l}\text { On treatment analysis, } \\
\text { between-group } \\
\text { domains }\end{array}$ \\
difference $(n=46)$ & difference $(n=33)$
\end{tabular}

Physical limitation

$$
\begin{aligned}
& \text { Baseline } \quad 48 \pm 25 \quad 50 \pm 20 \\
& 16 \text { weeks } \quad 40 \pm 19 \quad 60 \pm 24 \\
& \text { Change* }^{*}-7 \pm 27(p=0.31) \quad 6 \pm 20(p=0.22) \quad p=0.12 \quad p=0.13
\end{aligned}
$$

\begin{tabular}{|c|c|c|c|}
\hline Baseline & $39 \pm 28$ & $37 \pm 28$ & \\
\hline 16 weeks & $58 \pm 26$ & $55 \pm 27$ & \\
\hline Change $^{*}$ & $19 \pm 36(p=0.025)$ & $\begin{array}{l}18 \pm 32 \\
\quad(p=0.0093)\end{array}$ & $p=0.94$ \\
\hline
\end{tabular}

Angina stability

\begin{tabular}{|c|c|c|c|c|}
\hline Baseline & $65 \pm 24$ & $64 \pm 23$ & & \\
\hline 16 weeks & $81 \pm 23$ & $80 \pm 24$ & & \\
\hline Change $^{*}$ & $16 \pm 36(p=0.055)$ & $\begin{array}{l}15 \pm 27 \\
\quad(p=0.0095)\end{array}$ & $p=0.98$ & $p=0.66$ \\
\hline
\end{tabular}

Angina frequency

Treatment satisfaction

$$
\begin{array}{llll}
\text { Baseline } & 80 \pm 19 & 85 \pm 18 & \\
\text { 16 weeks } & 77 \pm 26 & 82 \pm 22 & \\
\text { Change }^{*} & -4 \pm 26(p=0.52) & -3 \pm 26(p=0.64) \quad p=0.89 & p=0.70
\end{array}
$$

Quality of life

$$
\begin{aligned}
& \begin{array}{lll}
\text { Baseline } & 37 \pm 24 & 45 \pm 27
\end{array} \\
& 16 \text { weeks } \quad 56 \pm 29 \quad 63 \pm 28 \\
& \text { Change }^{*} \quad 21 \pm 32(p=0.0067) \quad 18 \pm 31 \\
& (p=0.0083) \\
& p=0.76 \quad p=0.74
\end{aligned}
$$

*Within-group difference

more anti-angina therapies at baseline) versus relative ineffectiveness of ranolazine as an anti-angina agent [12]. There was also a strong placebo effect. For example, subjects randomized to placebo experienced a six-unit improvement in angina stability, a 15-unit improvement in angina frequency, and an 18-unit improvement in quality of life.
Inadequate power also remains a possible explanation for the lack of association between ranolazine and angina measures. While anti-angina therapy is an important treatment strategy among patients with ischemic heart disease [13], PCI has been shown to provide greater angina relief compared with optimal medical therapy [14]. 
Table 3 Change in subjective well-being from baseline to 16 weeks

\begin{tabular}{llll}
\hline $\begin{array}{l}\text { Subjective well-being } \\
\text { categories }\end{array}$ & Ranolazine $(\boldsymbol{n}=\mathbf{2 2})$ & Placebo $(\boldsymbol{n}=\mathbf{2 4})$ & $\begin{array}{l}\text { Between-group } \\
\text { difference }(\boldsymbol{p} \text { value })\end{array}$ \\
\hline $\begin{array}{l}\text { Excellent/good (\%) } \\
\text { Baseline }\end{array}$ & 40 & 24 & \\
16 weeks & 50 & 42 & 0.58 \\
Change & $10(p=0.50)$ & $18(p=0.19)$ & \\
Fair/poor (\%) & & & \\
Baseline & 56 & 68 & \\
16 weeks & 46 & 42 & 0.80 \\
Change* & $-11(p=0.48)$ & $-26(p=0.067)$ & \\
\hline
\end{tabular}

${ }^{*}$ Within-group difference

At the time this study was designed, RIVER-PCI was actively enrolling. Our findings were similar to the overall negative findings of the later reported RIVER-PCI trial [5]. In addition, among 864 patients enrolled with a chronic total occlusion in the RIVER-PCI trial, ischemia-driven revascularization or ischemia-driven hospitalization occurred in $27 \%$ of the ranolazine group versus $30 \%$ of the placebo group $(\mathrm{HR}=0.95$, 95\% CI $0.74-1.22, P_{\text {interaction }}=0.91$ ) [5]. This group is most similar to the characteristics of our study participants. There was also no improvement in angina burden from ranolazine versus placebo in the overall RIVER-PCI trial [15]. This study was intended to be a pilot study to investigate for any potential benefit in this patient population, and in so doing to estimate the sample size needed for a definitive study. However, given the lack of benefit in the present study, a larger study is not planned.

This study has some limitations. The primary outcome was relatively subjective; however, SAQ has been previously validated and is widely used in ischemic heart disease studies. In addition, a large proportion of patients discontinued the study medication; however, the rate of discontinuation was the same between study drug and placebo. The small sample size might have decreased to study power to detect statistically significant differences between both groups. Additionally, there was no difference in the intention-to-treat analysis versus the on-treatment analysis.

\section{CONCLUSIONS}

In conclusion, among subjects with chronic stable angina and documented myocardial ischemia, ranolazine did not improve the frequency of angina or subjective well-being at 16 weeks.

\section{ACKNOWLEDGMENTS}

Sponsorship for this study was funded by Gilead. No funding or sponsorship was received publication of this article. All named authors meet the International Committee of Medical Journal Editors (ICMJE) criteria for authorship for this manuscript, take responsibility for the integrity of the work as a 
whole, and have given final approval for the version to be published.

Disclosure. Anthony A. Bavry discloses the following relationship-Honorarium from American College of Cardiology. Ki E. Park, Calvin Y. Choi, Ahmed N. Mahmoud, Xuerong Wen and Islam Y. Elgendy have nothing to disclose.

Compliance with ethics guidelines. All procedures followed were in accordance with the ethical standards of the responsible committee on human experimentation (institutional and national) and with the Helsinki Declaration of 1964, as revised in 2013. Informed consent was obtained from all patients for being included in the study.

Data availability. The datasets during and/ or analyzed during the current study are available from the corresponding author on reasonable request.

Open Access. This article is distributed under the terms of the Creative Commons Attribution-NonCommercial 4.0 International License (http://creativecommons.org/licenses/ by-nc/4.0/), which permits any noncommercial use, distribution, and reproduction in any medium, provided you give appropriate credit to the original author(s) and the source, provide a link to the Creative Commons license, and indicate if changes were made.

\section{REFERENCES}

1. Hannan EL, Wu C, Walford G, et al. Incomplete revascularization in the era of drug-eluting stents: impact on adverse outcomes. JACC Cardiovasc Interv. 2009;2:17-25.
2. Rosner GF, Kirtane AJ, Genereux P, et al. Impact of the presence and extent of incomplete angiographic revascularization after percutaneous coronary intervention in acute coronary syndromes: the acute catheterization and urgent intervention triage strategy (ACUITY) trial. Circulation. 2012;125:2613-20.

3. Saad M, Mahmoud A, Elgendy IY, Richard Conti C. Ranolazine in cardiac arrhythmia. Clin Cardiol. 2016;39:170-8.

4. Morrow DA, Scirica BM, Karwatowska-Prokopczuk $\mathrm{E}$, et al. Effects of ranolazine on recurrent cardiovascular events in patients with non-ST-elevation acute coronary syndromes: the MERLIN-TIMI 36 randomized trial. JAMA. 2007;297:1775-83.

5. Weisz G, Genereux P, Iniguez A, et al. Ranolazine in patients with incomplete revascularisation after percutaneous coronary intervention (RIVER-PCI): a multicentre, randomised, double-blind, placebo-controlled trial. Lancet. 2016;387:136-45.

6. Elgendy IY, Conti CR, Bavry AA. Fractional flow reserve: an updated review. Clin Cardiol. 2014;37:371-80.

7. Elgendy IY, Choi C, Bavry AA. The impact of fractional flow reserve on revascularization. Cardiol Ther. 2015;4:191-6.

8. De Bruyne B, Pijls NH, Kalesan B, et al. Fractional flow reserve-guided PCI versus medical therapy in stable coronary disease. $\mathrm{N}$ Engl J Med. 2012;367:991-1001.

9. Spertus JA, Winder JA, Dewhurst TA, et al. Development and evaluation of the Seattle Angina Questionnaire: a new functional status measure for coronary artery disease. J Am Coll Cardiol. $1995 ; 25: 333-41$.

10. Ried LD, Tueth MJ, Handberg E, Nyanteh H. Validating a self-report measure of global subjective well-being to predict adverse clinical outcomes. Qual Life Res. 2006;15:675-86.

11. Dougherty CM, Dewhurst T, Nichol WP, Spertus J. Comparison of three quality of life instruments in stable angina pectoris: Seattle Angina Questionnaire, short form health survey (SF-36), and quality of life index-cardiac version III. J Clin Epidemiol. 1998;51:569-75.

12. Elgendy IY, Winchester DE, Pepine CJ. Experimental and early investigational drugs for angina pectoris. Expert Opin Investig Drugs. 2016;25:1413-21. 
13. Conti CR, Bavry AA, Petersen JW. Silent ischemia: clinical relevance. J Am Coll Cardiol. 2012;59:435-41.

14. Pursnani S, Korley F, Gopaul R, et al. Percutaneous coronary intervention versus optimal medical therapy in stable coronary artery disease: a systematic review and meta-analysis of randomized clinical trials. Circ Cardiovasc Interv. 2012;5:476-90.
15. Alexander KP, Weisz G, Prather K, et al. Effects of ranolazine on angina and quality of life after percutaneous coronary intervention with incomplete revascularization: results from the ranolazine for incomplete vessel revascularization (RIVER-PCI) trial. Circulation. 2016;133:39-47. 